\section{Growth and Net Photosynthetic Rate of Tomato Plantlets during Photoautotrophic and Photomixotrophic Micropropagation}

\author{
Chieri Kubota $^{1}$, Natsuko Kakizaki ${ }^{2}$, and Toyoki Kozai ${ }^{3}$ \\ Faculty of Horticulture, Chiba University, Matsudo, Chiba 271-8510, Japan
}

Koichi Kasahara and Jun Nemoto

Bio Research Center, Nicca Chemical Co., Ltd., 84 Kamihyogo, Fukui 9190526, Japan

Additional index words. carbon dioxide, controlled environment, Lycopersicon esculentum, photosynthetic photon flux, sugar, ventilation rate

Abstract. Nodal explants of tomato (Lycopersicon esculentum Mill.) were cultured in vitro to evaluate the effects of sugar concentration, photosynthetic photon flux $(P P F)$, $\mathrm{CO}_{2}$ concentration, ventilation rate of the vessel, and leaf removal on growth and photosynthesis. After 20 days of culture, the dry weights of plantlets derived from explants with leaves and cultured photoautotrophically (without sugar in the medium) under high $P P F$, high $\mathrm{CO}_{2}$ concentration, and high ventilation rate were more than twice as great as those of plantlets derived conventionally from explants without leaves and cultured photomixotrophically (with sugar in the medium) under low $P P F$, low $\mathrm{CO}_{2}$ concentration, and low ventilation rate (107 and $45 \mathrm{mg}$ per plantlet, respectively). Under photomixotrophic micropropagation conditions, the dry weights of plantlets from explants with leaves increased more than did those of plantlets from explants without leaves. High $P P F$, high $\mathrm{CO}_{2}$ concentration, and high ventilation rate increased net photosynthetic rate and promoted growth of the plantlets under photomixotrophic micropropagation conditions. Photomixotrophic conditions produced the greatest dry weight and the longest shoots, but photoautotrophic conditions produced the highest net photosynthetic rate. The number of leaves did not differ significantly between photoautotrophically and photomixotrophically cultured plantlets. Thus, photoautotrophic micropropagation is applicable to the production of high quality tomato transplants.

Photoautotrophic (sugar-free) micropropagation (PAM) has many advantages over conventional photomixotrophic micropropagation (PMM) in producing quality transplants. One such advantage is the low risk of contamination, which facilitates introducing large culture vessels [e.g., a 2.6-L vessel used by Kubota and Kozai (1992); a 12.8-L vessel used by Heo and Kozai (1999); a 100-L vessel used by Kirdmanee et al., (1995b)], and, thus, may reduce production costs. Another advantage of PAM is enhanced photosynthesis and growth of the plantlets. Kozai (1991) observed that photoautotrophically micropropagated plantlets of many species had higher net photosynthetic rates than

Received for publication 23 Aug. 1999. Accepted for publication $8 \mathrm{Apr}$. 2000. Mention of a trademark, proprietary product, or vendor does not constitute a guarantee or warranty of the product and does not imply its approval to the exclusion of other products or vendors that also may be suitable. The cost of publishing this paper was defrayed in part by the payment of page charges. Under postal regulations, this paper therefore must be hereby marked advertisement solely to indicate this fact.

${ }^{1}$ Associate Professor. E-mail address: ckubota@ midori.h.chiba-u.ac.jp

${ }^{2}$ Undergraduate Student.

${ }^{3}$ Professor

Table 1. Treatment descriptions in Expts. 1 and 2.

${ }^{y}$ Sucrose concentration in the medium.

${ }^{x} P P F$ on the empty culture shelf. photosynthetic rates when transplanted to ex vitro conditions (Donnelly and Vidaver, 1984). Enhanced net photosynthetic rates of Eucalyptus plantlets in vitro increased the survival percentage ex vitro (Kirdmanee et al., 1995a). These observations emphasize the significance of promoting photosynthesis in PAM. Therefore, PAM has been used in commercial transplant production and examined for a wide range of plant species (Roche et al., 1996).

Tomato is generally propagated by seeds, and, therefore, commercial micropropagation techniques for tomato plantlets are not well developed. Vegetative propagation of tomato, however, has recently been used for commercial production of genetically superior cultivars of heterozygous genotypes. The demand for those new cultivars has been increasing rapidly, and an immediate need is the development of techniques to propagate them efficiently. In conventional commercial micropropagation of tomato, plantlets are multiplied by using single node cuttings as propagules. The regenerated plantlets are either further divided into cuttings for successive multiplication or transplanted to the greenhouse. Vegetative propagation (using leafy cuttings as propagules) in the greenhouse is used following micropropagation because of the high cost of the latter. However, the difficulty of environmental control in the greenhouse often results in over- or underproduction of transplants, a major problem in production. Our aim is, therefore, to produce quality tomato transplants by PAM at lower cost and, ultimately, to eliminate the ex vitro propagation stage. The objective of this study was to examine the use of PAM for tomato and to compare the growth and net photosynthetic rate of plantlets cultured photoautotrophically vs. photomixotrophically (conventionally) under various cultural conditions.

\section{Materials and Methods} vitro plantlets is considered to be thec the low survival and growth rates in the acclimatization stage (Grout, 1978; Grout and Aston, 1978; Preece and Sutter, 1991). Raspberry (Rubus idaeus L.) plantlets grown photomixotrophically in vitro had low net Two experiments were conducted using 'HanaQueen' tomato. Single-node cuttings excised from plantlets cultured in vitro under

\begin{tabular}{|c|c|c|c|c|c|c|c|}
\hline \multirow[b]{2}{*}{ Treatments ${ }^{\mathrm{z}}$} & \multicolumn{2}{|c|}{ Explants } & \multirow{2}{*}{$\begin{array}{r}\text { Sucrose } \\
\text { concn }^{\mathrm{y}} \\
\left(\mathrm{g} \cdot \mathrm{L}^{-1}\right)\end{array}$} & \multirow{2}{*}{$\begin{array}{c}P P F^{\mathrm{x}} \text { before/ } \\
\text { after day } 8 \\
\left(\mu \mathrm{mol} \cdot \mathrm{m}^{-2} \cdot \mathrm{s}^{-1}\right)\end{array}$} & \multirow[b]{2}{*}{$\begin{array}{c}\mathrm{CO}_{2} \operatorname{concn}^{\mathrm{w}} \\
\left(\mu \mathrm{mol} \cdot \mathrm{mol}^{-1}\right)\end{array}$} & \multirow{2}{*}{$\begin{array}{c}\text { No. of air } \\
\text { exchanges }^{v} \\
\left(h^{-1}\right)\end{array}$} & \multirow{2}{*}{$\begin{array}{c}\text { Air temp } \\
\text { photo/dark- } \\
\text { period }\left({ }^{\circ} \mathrm{C}\right)\end{array}$} \\
\hline & $\begin{array}{c}\text { Leaf } \\
\text { removal }\end{array}$ & $\begin{array}{c}\text { Fresh wt } \\
(\mathrm{mg})\end{array}$ & & & & & \\
\hline & & & & Expt. 1 & & & \\
\hline PAM-WL & No & $111 \pm 16$ & 0 & $70 / 130$ & $1500 \pm 100$ & $4.2 \pm 0.5$ & $24 / 24$ \\
\hline PMM-WL & No & $110 \pm 20$ & 30 & $50 / 50$ & $450 \pm 50$ & $1.0 \pm 0.1$ & $24 / 24$ \\
\hline PMM-WOL & Yes & $60 \pm 10$ & 30 & $50 / 50$ & $450 \pm 50$ & $1.0 \pm 0.1$ & $24 / 24$ \\
\hline PAM-H & No & $204+24$ & 0 & $\begin{array}{l}\text { Expt. } 2 \\
100 / 100\end{array}$ & & $42+$ & $24 / 21$ \\
\hline PMM-H & No & $203 \pm 27$ & 30 & $100 / 100$ & $1300 \pm 100$ & $4.2 \pm 0.5$ & $24 / 21$ \\
\hline PMM-L & No & $205 \pm 23$ & 30 & $50 / 50$ & $450 \pm 50$ & $1.0 \pm 0.1$ & $24 / 21$ \\
\hline
\end{tabular}

${ }^{\mathrm{z}} \mathrm{PAM}=$ photoautotrophic micropropagation, $\mathrm{PMM}=$ photomixotrophic micropropagation, $\mathrm{WL}=$ explants with leaves, WOL = explants without leaves, $\mathrm{H}=$ high $P P F$, high $\mathrm{CO}_{2}$ concentration, and high ventilation conditions, and $\mathrm{L}=$ low $P P F$, low $\mathrm{CO}_{2}$ concentration, and low ventilation conditions.

${ }^{\text {w}}$ Carbon dioxide concentration outside the vessels (inside the culture room).

${ }^{v}$ Number of air exchanges of the vessel estimated according to Kozai et al. (1986). 
conventional culture conditions were used as explants. The treatments are described in Table 1. The explants were cultured in 480$\mathrm{mL}$ polycarbonate vessels (Nicca Chemical Co., Fukui, Japan) containing $80-\mathrm{mL}$ of Murashige and Skoog (1962) gelled (Gelrite, $\left.3 \mathrm{~g} \cdot \mathrm{L}^{-1}\right)$ medium. Number of air exchanges of the vessel (Kozai et al., 1986) was varied by the number of gas-permeable filter disks ( $10 \mathrm{~mm}$ in diameter, pore size $0.5 \mu \mathrm{m}$, MilliSeal, Millipore, Tokyo) attached to the lid of the vessel. White fluorescent tubes (EPL55EX-N; Matsushita Electric Industrial Co., Kyoto, Japan) were used as a light source, providing a $16-\mathrm{h}$ photoperiod. The $P P F$ was adjusted by varying the number of fluorescent tubes above the culture shelf. Air temperature inside the vessel was monitored throughout the experiments using a $0.1-\mathrm{mm}$ copper-constantan thermocouple. Relative humidity $(\mathrm{RH})$ in the culture room was maintained at $80 \% \pm 10 \%$.

Expt. 1 was designed for two objectives: to compare plantlet growth under PAM vs. conventional PMM conditions, and to examine the effects of leaf removal from the explants on growth under PMM conditions. Leaf removal is a common practice in conventional micropropagation, probably because of the difficulty in handling explants with large leaves. In the present experiment, explants were prepared with either two leaflets or none per explant, and four explants were cultured per vessel. Explants with leaves were cultured photoautotrophically [PAMwith-leaves (PAM-WL) treatment] under conditions of high $P P F\left(130 \mu \mathrm{mol} \cdot \mathrm{m}^{-2} \cdot \mathrm{s}^{-1}\right.$ for days 8 to 20), high $\mathrm{CO}_{2}$ concentration (1500 $\left.\mu \mathrm{mol} \cdot \mathrm{mol}^{-1}\right)$, and high ventilation rate of the vessel (4.2 air exchanges per hour). Explants with or without leaves were cultured photomixotrophically [PMM-with-leaves (PMMWL) and PMM-without-leaves (PMM-WOL), respectively] under conventional conditions of low PPF $\left(50 \mu \mathrm{mol} \cdot \mathrm{m}^{-2} \cdot \mathrm{s}^{-1}\right)$, low $\mathrm{CO}_{2}$ concentration $\left(450 \mu \mathrm{mol} \cdot \mathrm{mol}^{-1}\right)$, and low ventilation rate of the vessel (1.0 air exchanges per hour). The PMM-WOL treatment is considered as a conventional culture method.

Expt. 2 was designed to observe the effects of $P P F, \mathrm{CO}_{2}$ concentration, ventilation rate of the vessel, and sugar concentration in the medium on the growth and net photosynthetic rate of plantlets. Explants with leaves were cultured either photoautotrophically (PAM$\mathrm{H})$ or photomixotrophically (PMM-H) under conditions of high $P P F\left(100 \mu \mathrm{mol} \cdot \mathrm{m}^{-2} \cdot \mathrm{s}^{-1}\right)$, high $\mathrm{CO}_{2}$ concentration $\left(1300 \mu \mathrm{mol} \cdot \mathrm{mol}^{-1}\right)$, and high ventilation rate (4.2 air exchanges per hour), using three explants per vessel. Explants with leaves were also cultured photomixotrophically under low $P P F$ (50 $\left.\mu \mathrm{mol} \cdot \mathrm{m}^{-2} \cdot \mathrm{s}^{-1}\right)$, low $\mathrm{CO}_{2}\left(450 \mu \mathrm{mol} \cdot \mathrm{mol}^{-1}\right)$, and low ventilation rate (1.0 air exchanges per hour) (PMM-L).

Measurement and calculation. At the end of 20-d culture period, four vessels (16 and 12 plantlets in Expts. 1 and 2, respectively) were harvested, and fresh weight, shoot length, number of unfolded leaves, and leaf area of each plantlet were measured. Dry weight of the plantlet was measured after drying at $60{ }^{\circ} \mathrm{C}$ for $48 \mathrm{~h}$. Carbon dioxide concentrations inside and outside the vessels (five and four vessels in Expts. 1 and 2, respectively) were measured once every $5 \mathrm{~d}$ using a gas chromatograph (GC-9A; Shimadzu Co., Kyoto, Japan) when the $\mathrm{CO}_{2}$ concentrations were stable during the photo- and the dark periods. Carbon dioxide exchange rates (CER) of the plantlets were calculated from the difference in $\mathrm{CO}_{2}$ concentrations inside and outside the vessel, number of air exchanges, and the volume of the vessel, as described by Fujiwara et al. (1987). The CER is positive for plantlets with higher $\mathrm{CO}_{2}$ uptake rates than $\mathrm{CO}_{2}$ evolution rates (i.e., net photosynthetic rate is positive). The CER per leaf area was calculated from the CER per plantlet and the leaf area per plantlet on day 20.

Expt. 1 was conducted once. Expt. 2 was conducted twice, but the data from only one experiment are presented, since the same trend was obtained in both. For statistical analysis, each vessel containing four (Expt. 1) or three (Expt. 2) plantlets was considered as a replication. The statistical differences between treatments were analyzed by the LSD test when analysis of variance (ANOVA) indicated treatment significance.

\section{Results and Discussion}

Expt. 1. Effects of explant leaf removal and photoautotrophic and photomixotrophic (conventional) micropropagation conditions on the growth and net photosynthetic rates of the plantlets. The total dry weight per plantlet was more than twice as great in the PAM-WL and the PMM-WL treatments as in the PMMWOL treatment (Table 2). Leaf and stem dry weights in the PAM-WL and the PMM-WL treatments did not differ significantly. Leaf dry weight was the lowest in the PMM-WOL treatment. Root dry weight was greater in the PMM-WL treatment than in the other two treatments, but neither shoot length nor number of leaves was significantly affected. This indicates that the multiplication rate did not differ among treatments, since the plantlets were propagated using single node cuttings, and the number of leaves equals the number of single node cuttings obtained per plantlet.

The CER per plantlet during the photoperiod (=net photosynthetic rate per plantlet) increased with time in the PAM-WL treatment, while that of the PMM-WL and the PMM-WOL plantlets remained almost zero (Fig. 1B). The CER per leaf area of PAM-WL plantlets during the photoperiod on day 20 was 16 and 6.5 times that of the PMM-WL and the PMM-WOL plantlets, respectively (Table 2). The ratios of hourly CER per unit leaf area during the photoperiod to the absolute value of that during the dark period (P/D ratio) on day 20 were 1.9 in the PAM-WL treatment, and 0.1 and 0.3 in the PMM-WL and the PMM-WOL treatments respectively, indicating that the daily CER per leaf area was positive in the PAM-WL treatment but negative in the PMM-WL and PMM-WOL treatments. The estimated daily CER per unit leaf area (= sum of 16 times hourly CER per $\mathrm{m}^{2}$ during the 16 -h photoperiod and 8 times hourly CER per $\mathrm{m}^{2}$ during the 8 -h dark period) were $7.1,-1.4$, and $-1.0 \mathrm{mmol} \cdot \mathrm{m}^{-2} \cdot \mathrm{d}^{-1}$ in the PAM-WL, PMM-WL, and PMM-WOL treatments, respectively. The low $\mathrm{P} / \mathrm{D}$ ratio and negative daily CER indicated that growth in the PMM-WL and PMM-WOL treatments was probably more dependent on the sugar in the medium than on the $\mathrm{CO}_{2}$ in the air, regardless of leaf removal. For a complete understanding of carbon balance, gross photosynthesis and sugar uptake from the medium will need to be estimated.

Growth promotion under PAM conditions with high $P P F$, high $\mathrm{CO}_{2}$ concentration, and high ventilation rate has often been observed in many plant species, including those in the Solanaceae (Kozai, 1991). In the present experiment, however, the growth of tomato plantlets in the PAM-WL treatment under high $P P F$, high $\mathrm{CO}_{2}$ concentration, and high ventilation rate was similar to that in the PMM-WL treatment under low $P P F$, low $\mathrm{CO}_{2}$ concentration, and low ventilation rate. Net photosynthetic rates of tomato plantlets cultured in vitro increased with increasing $P P F$ when $P P F$ was lower than $1000 \mu \mathrm{mol} \cdot \mathrm{m}^{-2} \cdot \mathrm{s}^{-1}$ (Niu et al., 1998). Increasing $P P F$ might have enhanced the CER and growth rate of the plantlets in the present experiment. The $\mathrm{CO}_{2}$ concentration inside the vessel decreased with increasing duration of culture (Fig. 1A). Maintaining $\mathrm{CO}_{2}$ concentration inside the vessel at higher levels than those in Expt. 1 throughout the culture period might also enhance the growth rate of the plantlets and reduce the culture period in the PAM-WL treatment.

Relative growth rates of the plantlets, calculated from the dry weight increase for $20 \mathrm{~d}$, were 0.6 and $0.4 \mathrm{~g} \cdot \mathrm{g}^{-1} \cdot \mathrm{d}^{-1}$ in the PMMWL and the PMM-WOL treatments, respectively. This means that the greater growth in the PMM-WL treatment was not caused by use of explants with greater dry weight. Growth promotion observed under PMM conditions is generally due to either a greater photosynthetic rate or enhanced uptake of sugar from the medium, or both. The hourly CER during the photoperiod on day 5 was negative in the PMM-WOL treatment, but positive and significantly greater in the PMMWL treatment than in the PMM-WOL treatment (Fig. 1B). Thus, the growth promotion with leafy explants was partly the result of the increased net photosynthetic rates during the first 5 to $10 \mathrm{~d}$ of culture. In conventional micropropagation, explant size affects the multiplication rate in early stages of shoot culture (George, 1993), but few data are available as to the effects of explant leaf removal. Under PAM conditions, use of explants with large leaf area reportedly promoted the growth of potato (Solanum tuberosum L.) plantlets (Miyashita et al., 1996). In the present experiment, sugar uptake from the medium by the plantlets under PMM conditions might have been enhanced when leafy explants were used, but this remains uncertain.

Expt. 2. Effects of sugar in the medium 


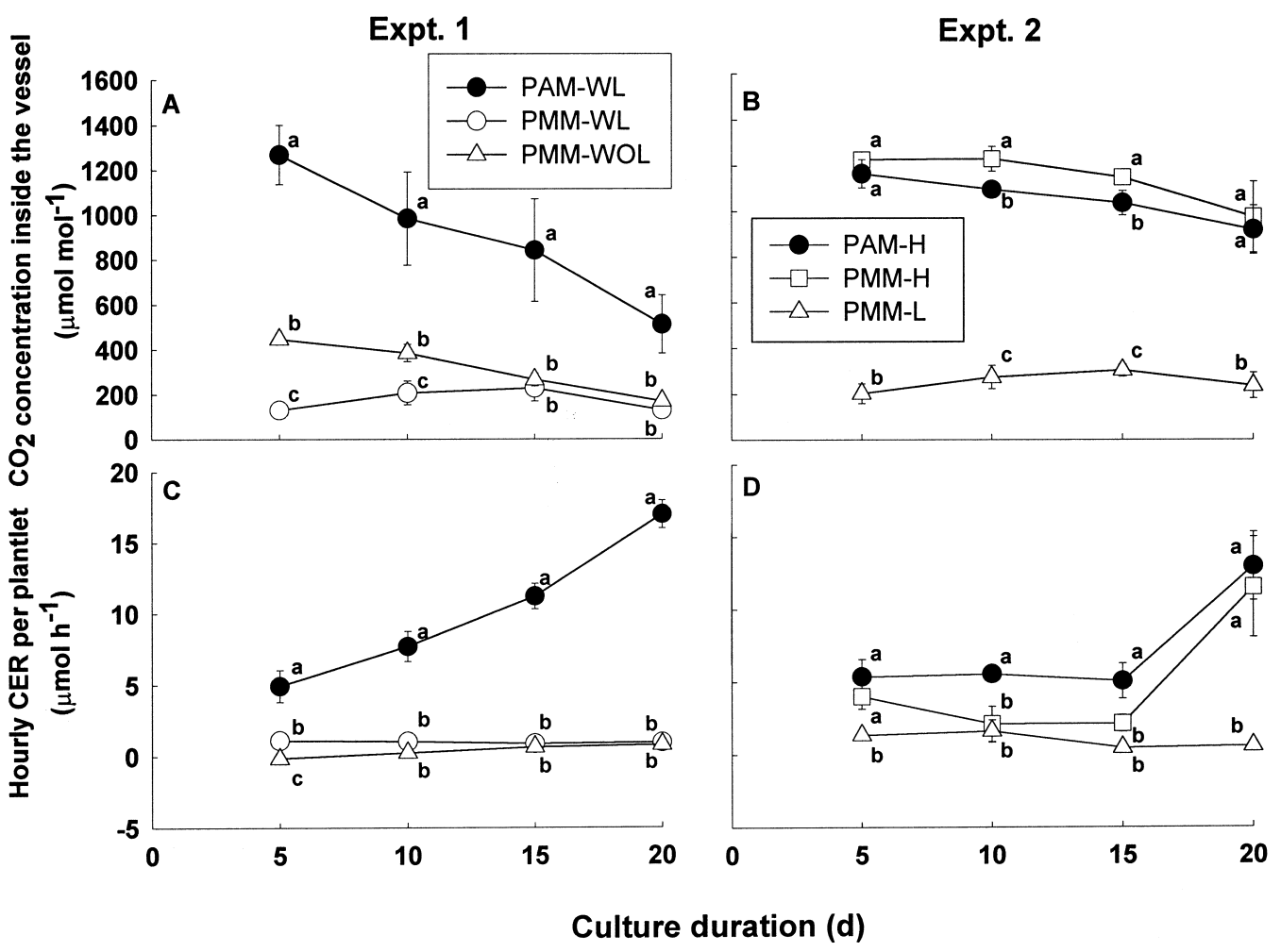

Fig. 1. (A, B) $\mathrm{CO}_{2}$ concentration over $20 \mathrm{~d}$ of culture inside $480 \mathrm{~mL}$ vessel containing three or four tomato plantlets grown under six culture conditions. (C, D) Hourly $\mathrm{CO}_{2}$ exchange rate (CER) per tomato plantlet under six culture conditions during the photoperiod. See Table 1 for treatment descriptions. Means \pm SD are shown ( $\mathrm{n}=5$ in Expt. $1 ; \mathrm{n}=4$ in Expt. 2). Means separation within days by LSD at $P \leq 0.01$.

Table 2. Effects of sugar in the medium, explant leaf removal, and increased $P P F, \mathrm{CO}_{2}$ concentration and ventilation of the vessel on dry weight of tomato plantlet parts, shoot length, number of leaves per plantlet, and $\mathrm{CO}_{2}$ exchange rates (CER) per leaf area during the photo- and the dark period on day 20.

\begin{tabular}{|c|c|c|c|c|c|c|c|c|}
\hline \multirow[b]{2}{*}{ Treatment } & \multicolumn{4}{|c|}{ Dry wt per plantlet ${ }^{2}(\mathrm{mg})$} & \multirow{2}{*}{$\begin{array}{c}\text { Shoot length } \\
(\mathrm{mm})\end{array}$} & \multirow{2}{*}{$\begin{array}{c}\text { No. of leaves } \\
\text { per plantlet }\end{array}$} & \multicolumn{2}{|c|}{ CER $\left(\mu \mathrm{mol} \cdot \mathrm{m}^{-2} \cdot \mathrm{h}^{-1}\right)$} \\
\hline & Total & Leaf & Stem & Root & & & Photoperiod & Dark period \\
\hline & & & & & Expt. 1 & & & \\
\hline PAM-WL & $107 a^{y}$ & $32 \mathrm{a}$ & $9 \mathrm{a}$ & $17 \mathrm{~b}$ & $40 \pm 4$ & $3 \pm 0.5$ & $608 \mathrm{a}$ & $-328 \pm 57$ \\
\hline PMM-WL & $105 \mathrm{a}$ & $32 \mathrm{a}$ & $8 \mathrm{ab}$ & $27 \mathrm{a}$ & $38 \pm 5$ & & $38 \mathrm{~b}$ & $-254 \pm 41$ \\
\hline PMM-WOL & $45 \mathrm{~b}$ & $17 \mathrm{~b}$ & $4 \mathrm{~b}$ & $10 \mathrm{~b}$ & $28 \pm 9$ & $4 \pm 0.5$ & $93 \mathrm{~b}$ & $-313 \pm 41$ \\
\hline & & & & & Expt. 2 & & & \\
\hline PAM-H & $88 \mathrm{~b}$ & $22 \mathrm{~b}$ & $26 \mathrm{~b}$ & $9 \mathrm{~b}$ & $34 \mathrm{~b}$ & 0.3 & $1172 \mathrm{a}$ & $-738 a$ \\
\hline PMM-H & $178 \mathrm{a}$ & $49 \mathrm{a}$ & $61 \mathrm{a}$ & $37 \mathrm{a}$ & 78 & & $482 \mathrm{~b}$ & $-708 \mathrm{a}$ \\
\hline PMM-L & $89 \mathrm{~b}$ & $29 \mathrm{~b}$ & $22 \mathrm{~b}$ & $16 \mathrm{~b}$ & $35 \mathrm{~b}$ & $4 \pm 0.3$ & $40 \mathrm{c}$ & $-321 b$ \\
\hline
\end{tabular}

${ }^{2}$ Total dry weight includes leaf, stem, root and explant dry weights. Leaf, stem and root dry weights denote the dry weight of the identical part of the newly developed shoot.

${ }^{y}$ Mean separation within columns and experiments by LSD test at $P<0.01$. Means $\pm \mathrm{SD}(\mathrm{n}=4)$ are shown for observations where ANOVA did not indicate significant differences among treatments.

and conditions of high PPF and high $\mathrm{CO}_{2}$ concentration, and high ventilation rate of the vessel on the growth and net photosynthetic rates of plantlets. The total dry weight per plantlet was twice as great in the PMM-H treatment as in the PAM-H or the PMM-L treatment (Table 2), and dry weights of leaves, stems and roots, and stem length were 1.74.1 times as great as in the PAM-H and the PMM-L treatments. Number of leaves was not affected. Rate of plantlet production is important in micropropagation. Environmental conditions should be selected to enhance number of leaves when nodal cuttings are used as propagules. The difference in size of plantlets (fresh and dry weights and leaf area) may affect their growth after transplanting ex vitro, but we did not investigate this. In micropropagation of tomato, regenerated plantlets are either used as stock plants for successive multiplication or transplanted to a greenhouse. Therefore, high net photosynthetic rates need to be achieved in vitro without reducing multiplication rates.

Carbon dioxide concentration inside the vessel during the photoperiod was slightly lower in the PAM-H than in the PMM-H treatment on days 10 and 15 (Fig. 1C), and the hourly CER per plantlet during the photoperiod was highest in the PAM-H treatment, followed by the PMM-H and the PMM-L treatments. Although the hourly CER per plantlet on day 20 did not differ between the PAM-H and PMM-H treatments during the photoperiod, the hourly CER per unit leaf area was 2.4 times as great in the PAM-H as in the PMM-H treatment during the photoperiod (Table 2). The conditions of high $P P F$, high $\mathrm{CO}_{2}$ concentration, and high ventilation rate increased the hourly CER per unit leaf area under PMM conditions; however, the rate in the PMM-H treatment was still less than half of that in the PAM-H treatment, although the $\mathrm{CO}_{2}$ concentrations inside the vessel were similar in the two treatments. This means that the plantlets had higher photosynthetic abilities in the PAM-H than in PMM-H treatment. This agrees with the general observation that the photosynthesis of plantlets in vitro is suppressed when cultured with sugar in the medium (Desjardins, 1995). The P/D ratios on day 20 were $1.6,0.7$, and 0.1 , and the estimated daily CER per unit leaf area was $12.8,2.0$, and $-1.9 \mathrm{mmol} \cdot \mathrm{m}^{-2} \cdot \mathrm{d}^{-1}$ in the PAM-H, PMM-H, and PMM-L treatments, respectively. The greater $\mathrm{P} / \mathrm{D}$ ratio and daily CER in the PMM-H than in the PMM-L treatment indicates that the increased net photosynthetic rate under high $P P F$, high $\mathrm{CO}_{2}$ concentration, and high ventilation conditions contributed to the growth promotion in the former treatment, and that such plantlets were more dependent on photosynthesis than were the PMM-L plantlets.

Photoautotrophic micropropagation using explants with leaves under high $P P F$, high $\mathrm{CO}_{2}$ concentration, and high ventilation rate promoted both growth and photosynthesis without reducing multiplication rate. Photomixotrophic micropropagation under similar 
cultural conditions induced greater growth but reduced photosynthetic ability. Promoting photosynthesis of plantlets during in vitro culture is considered important, but further study will be needed to compare the ex vitro performance of those plantlets.

\section{Literature Cited}

Desjardins, Y. 1995. Factors affecting $\mathrm{CO}_{2}$ fixation in striving to optimize photoautotrophy in micropropagated plantlets. Plant Tissue Cult. Biotech. 1:13-25.

Donnelly, D.J. and W.E. Vidaver. 1984. Pigment content and gas exchanges of red raspberry in vitro and ex vitro. J. Amer. Soc. Hort. Sci. 109:177-181.

Fujiwara, K., T. Kozai, and I. Watanabe. 1987. Fundamental studies on environments in plant tissue culture vessels. (3) Measurements of carbon dioxide gas concentration in closed vessels containing tissue-cultured plantlets and estimates of net photosynthetic rates of the plantlets (in Japanese with English summary). J. Agr. Meteorol. 43:21-30.

George, E.F. 1993. Plant propagation by tissue culture. Part 1. The technology. Exegetics, Edington, England.

Grout, B.W.W. 1978. Transplanting of cauliflower plants regenerated from meristem culture. II. Carbon dioxide fixation and the development of photosynthetic ability. Hort. Res. 17:65-71.

Grout, B.W.W. and M.J. Aston. 1978. Modified leaf anatomy of cauliflower plantlets regenerated from meristem culture. Ann. Bot. 42:993995.

Heo, J.W. and T. Kozai. 1999. Forced ventilation micropropagation system for enhancing photosynthesis, growth and development of sweetpotato plantlets. Environ. Control Biol. 37:83-92.

Kirdmanee, C., Y. Kitaya, and T. Kozai. 1995a. Effects of $\mathrm{CO}_{2}$ enrichment and supporting material in vitro on photoautotrophic growth of $\mathrm{Eu}$ calyptus plantlets in vitro and ex vitro. In Vitro Cell. Dev. Biol. Plant 31:144-149.

Kirdmanee, C., Y. Kitaya, and T. Kozai. 1995b. Rapid acclimatization of Eucalyptus plantlets by controlling photosynthetic photon flux and relative humidity. Environ. Control Biol. 33:123132.

Kozai, T. 1991. Micropropagation under photoautotrophic conditions, p. 447-469. In: P.C. Debergh and R.H. Zimmerman (eds.). Micropropagation. Kluwer Academic, Dordrecht.

Kozai, T., K. Fujiwara, and I. Watanabe. 1986. Fundamental studies on environments in plant tissue culture vessels. (2) Effects of stoppers and vessels on gas exchange rates between inside and outside of vessels closed with stoppers. (In Japanese with English summary) J. Agr. Meteorol. 42:119-127.

Kubota, C. and T. Kozai. 1992. Growth and net photosynthetic rate of Solanum tuberosum in vitro under forced and natural ventilation. HortScience 27:1312-1314.

Miyashita, Y., Y. Kitaya, C. Kubota, and T. Kozai. 1996. Photoautotrophic growth of potato plantlets as affected by explant leaf area, fresh weight and stem length. Scientia Hort. 65:199-202.

Murashige, T. and F. Skoog. 1962. A revised medium for rapid growth and bioassays with tobacco tissue cultures. Physiol. Plant. 15:473-497.

Niu, G., T. Kozai, and C. Kubota. 1998. A system for measuring the in situ $\mathrm{CO}_{2}$ exchange rates of in vitro plantlets. HortScience 33:1076-1078.

Preece, J.E. and E.G. Sutter. 1991. Acclimatization of micropropagated plants to the greenhouse and field, p. 71-93. In: P. Debergh and R. Zimmerman (eds.). Micropropagation technology and application. Kluwer Academic Dordrecht.

Roche, T.D., R.D. Long, A.J. Sayegh, and M.J. Hennerty. 1996. Commercial-scale photo-autotrophic micropropagation: Applications in Irish agriculture, horticulture and forestry. Acta Hort. 440:515-520. 